\title{
Production Behavior of Fractured Horizontal Well in Closed Rectangular Shale Gas Reservoirs
}

\author{
Qiguo Liu, ${ }^{1}$ Ke Li, ${ }^{1}$ Weihong Wang, ${ }^{2,3}$ Xiaohu Hu, ${ }^{2,3}$ and Hua Liu ${ }^{2,3}$ \\ ${ }^{1}$ School of Oil \& Gas Engineering, Southwest Petroleum University, Chengdu, Sichuan, China \\ ${ }^{2}$ SINOPEC Exploration \& Production Research Institute, China Petroleum \& Chemical Corporation, Beijing, China \\ ${ }^{3}$ State Key Laboratory of Shale Oil and Gas Enrichment Mechanisms and Effective Development, \\ China Petroleum \& Chemical Corporation, Beijing, China
}

Correspondence should be addressed to Qiguo Liu; liuqiguo@swpu.edu.cn

Received 15 October 2015; Revised 13 January 2016; Accepted 17 January 2016

Academic Editor: Nazrul Islam

Copyright (C) 2016 Qiguo Liu et al. This is an open access article distributed under the Creative Commons Attribution License, which permits unrestricted use, distribution, and reproduction in any medium, provided the original work is properly cited.

\begin{abstract}
This paper established a triple porosity physical model in rectangular closed reservoirs to understand the complex fluid flowing mechanism and production behavior of multifractured horizontal wells in shale gas reservoirs, which is more appropriate for practical situation compared with previous ones. According to the seepage theory considering adsorption and desorption process in stable state, the gas production rate of a well producing at constant wellbore pressure was obtained by utilizing the methods of Green's and source function theory and superposition principle. Meanwhile, the volume of adsorbed gas $\left(G_{\mathrm{L}}\right)$ and the number of hydraulic fractures $(M)$ as well as permeabilities of matrix system $\left(k_{\mathrm{m}}\right)$ and microfractures $\left(k_{\mathrm{f}}\right)$ were discussed in this paper as sensitive factors, which have significant influences on the production behavior of the wells. The bigger the value of $G_{\mathrm{L}}$ is, the larger the well production rate will be in the later flowing periods, and the differences of production rate with the increasing of $M$ are small, which manifest that there is an optimum $M$ for a given field. Therefore, the study in this paper is of significant importance to understand the dynamic production declining performance in shale gas reservoirs.
\end{abstract}

\section{Introduction}

Some researches show that the reserves of shale gas in current world have reached $456 \times 10^{12} \mathrm{~m}^{3}$ [1], which equals the sum of coal-bed methane and tight sand gas reserves. That is to say, shale gas has become the most important energy source and a key component of the energy supply in the world. In order to develop the shale gas reservoirs more economically and efficiently, it is necessary to take advantage of horizontal well drilling technology and multistage hydraulic fracturing, which can not only improve conductivity of hydraulic fractures, but also activate and connect existing natural fractures generating large spatial network system. So these technologies have been proved as the most effective method in developing shale gas reservoirs until now.

Due to the unique features, unconventional reservoirs are often characterized by dual-porosity model [2], in which matrix has lower permeability but contains most of the gas, while fractures have greater flow conductivity as the main flow channel. Existing in rock matrix and fractures, natural gas in shale formation is commonly described by dual-porosity models. According to the previous theoretical research and field tests [1, 3-9], an identical conclusion has been reached that both hydraulic fractures and natural fractures play important roles in production performance in shale gas reservoirs.

However, it has been proved that seepage flow in shale gas reservoirs is much more complicated than that in conventional gas reservoirs because of massive multistage, multicluster hydraulic fracturing stimulations. It is urgent to propose some new methods to simulate these complex flowing systems better and to help understand the recovery mechanism as well as optimizing development plans of shale gas reservoirs. Therefore, many researchers have done a great amount of studies on fluid seepage in horizontal wells and transient pressure analysis for shale gas reservoirs in recent years. Different models have been built to illustrate different flow mechanism in shale formations. 
The transient pressure behavior of wells in shale gas reservoirs was first studied by Kucuk and Sawyer [10] who utilized the analytical method and numerical simulation to do the research. However, they did not take the effect of desorption and diffusion into consideration, which are the typical characteristics of shale gas. This may cause big error in production analysis during the practical development.

In 2010, Ozkan et al. [6] took the diffusive flow mechanism into consideration and used analytical method to build up the dual-mechanism dual-porosity multiply fractured horizontal well model for shale gas reservoirs. But they neglected adsorption gas on matrix particle surface, which may cause great deviation with shale gas production behavior.

Aiming to describe the flow mechanism in shale matrix, triple-porosity linear flow model was built by Al-Ahmadi and Wattenbarger [11], where they took the impact of shale gas desorption into their physical and mathematical model. However, the disadvantage in their paper was that the shale gas diffusion in matrix was neglected.

Zhao et al. [12] took reference to former studies and presented a new concept called "triporosity" mathematical model to describe fluid flow from shale gas formation to a multifractured horizontal well while analyzing the production decline when a well is producing at a constant wellbore pressure. But the physical model in their paper was built up on the condition that the layer is infinite, which is not always in accordance with actual situation.

Based on the models established by previous scholars, Wang [13] provided a new well testing model with consideration of desorption, diffusive flow, viscous flow, and stress-sensibility of reservoir permeability for multifractured horizontal wells in shale gas reservoirs. However, the shale gas production behavior was not discussed in his research.

Assuming an analytical model with the consideration of adsorption and diffusive flow process, Sang et al. [14] analyzed the transient pressure performance of multiple fractured horizontal wells in unconventional shale reservoirs. Although they discussed the influence on production behavior caused by different bottom-hole pressure and Langmuir pressure, some key factors were neglected such as the number of hydraulic fractures.

The work done by $\mathrm{Xu}$ et al. [15] was identical with the former scholar's. Not only did they set up physical model and discuss the transient pressure behavior, but also they analyzed the production performance. But they considered that the outer boundary is infinite, which may not be true in actual situations.

In view of these factors, the physical model in this research was based on the condition of a multistage fractured horizontal well in a rectangular closed reservoir, since the constant pressure curves could form a nearly rectangular region, according to the seepage theory and practical production data $[1,16]$. Applying the triple-porosity model with considering adsorption and desorption in stable state, a novel model to describe the fluid flow behaviors in shale gas reservoirs is established and the corresponding solutions are derived by Green's and source function and superposition principle, which can make up the defects of previous ones and can be more effective in guiding the practical production.

\section{Gas Adsorption/Desorption Model}

Gas adsorption is a surface phenomenon and is predominately a physical bond caused by the intermolecular attractive forces, such as Van der Waals forces, while desorption is the converse process of adsorption [18].

Although there are many adsorption models that were introduced to describe the adsorption/desorption characteristics of gas molecular on particle surface, the Langmuir model is the most commonly used. The mathematical expression of this model is

$$
G_{\mathrm{ads}}=\frac{G_{\mathrm{L}} p_{\mathrm{m}}}{p_{\mathrm{L}}+p_{\mathrm{m}}} .
$$

For most reservoirs, reservoir temperature can be treated as constant only if the reservoirs are injected with other cool or hot fluid. So, for the adsorption/desorption model, an assumption that temperature does not change for the problem is under consideration. That is the reason why people always called the Langmuir formula "sorption isotherm." A typical adsorption isotherm curve (Langmuir curve) is illustrated in Figure 1.

\section{Physical Model}

It has been reported that there existed many organic pores in the formation of shale gas reservoir from SEM images, and the scale of these pores is much larger than the molecular diameter of methane, so this will cause some errors if gas storage and seepage in matrix pores were not taken into account in shale matrix. In order to overcome this problem, some scholars proposed a triple-porosity model to consider the effects of these large scale pores on well production performance, which means that the absorbed gas would firstly flow into matrix pores rather than microfracture, and then it would flow into microfractures from matrix pores. The flowing process can be clearly schematized by the following illustrations (Figure 2) [12, 17].

In spherical coordinate system, the continuity equation of shale gas flowing in fractures was presented by Kucuk and Sawyer [10] as follows:

$$
\frac{1}{r^{2}} \frac{\partial}{\partial r}\left(\frac{k_{\mathrm{f}}}{\mu_{\mathrm{g}}} \rho_{\mathrm{g}} r^{2} \frac{\partial p_{\mathrm{f}}}{\partial r}\right)+q_{\mathrm{m}}=\frac{\partial\left(\phi_{\mathrm{f}} \rho_{\mathrm{g}}\right)}{\partial t} .
$$

According to the Warren and Root model [2], the governing flow equation in matrix pores can be described by the following formula for the pseudosteady state flow:

$$
-q_{\mathrm{m}}=\frac{\partial\left(\phi_{\mathrm{m}} \rho_{\mathrm{g}}\right)}{\partial t}+q_{\mathrm{des}} .
$$

And For pseudosteady state interporosity flow model, the equation of gas flow from matrix pores to microfractures is

$$
q_{\mathrm{m}}=\frac{\alpha k_{\mathrm{m}}}{\mu_{\mathrm{g}}}\left(\rho_{\mathrm{gm}} p_{\mathrm{m}}-\rho_{\mathrm{gf}} p_{\mathrm{f}}\right) .
$$




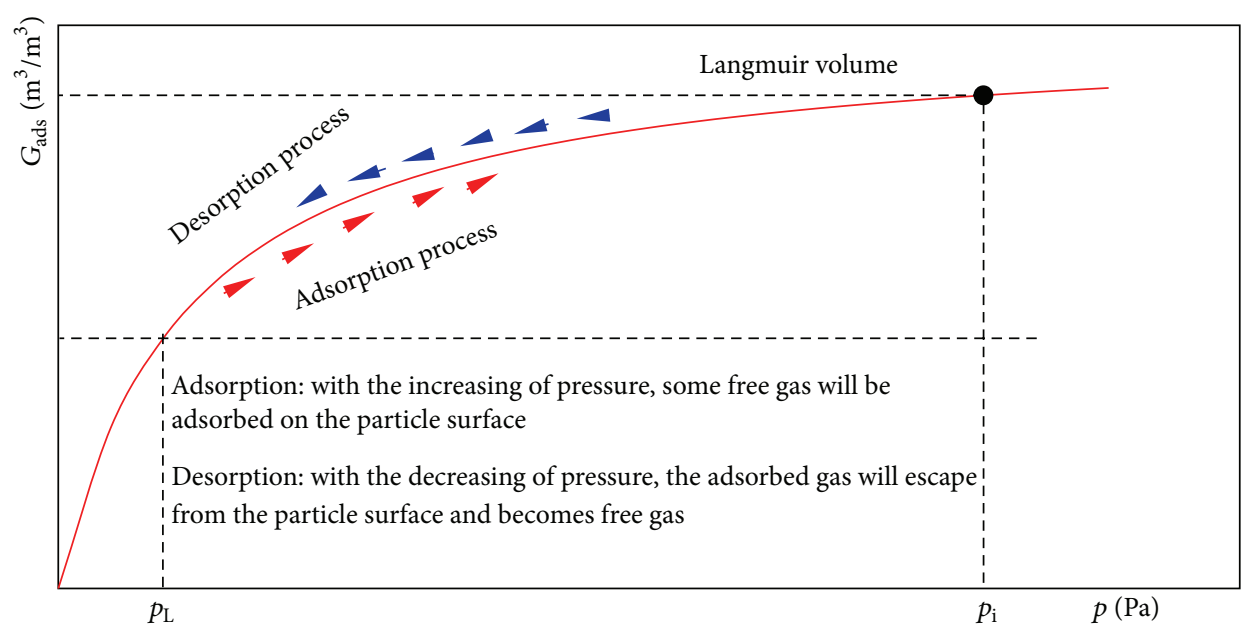

FIGURE 1: Illustration of typical gas adsorption/desorption isotherm curve.

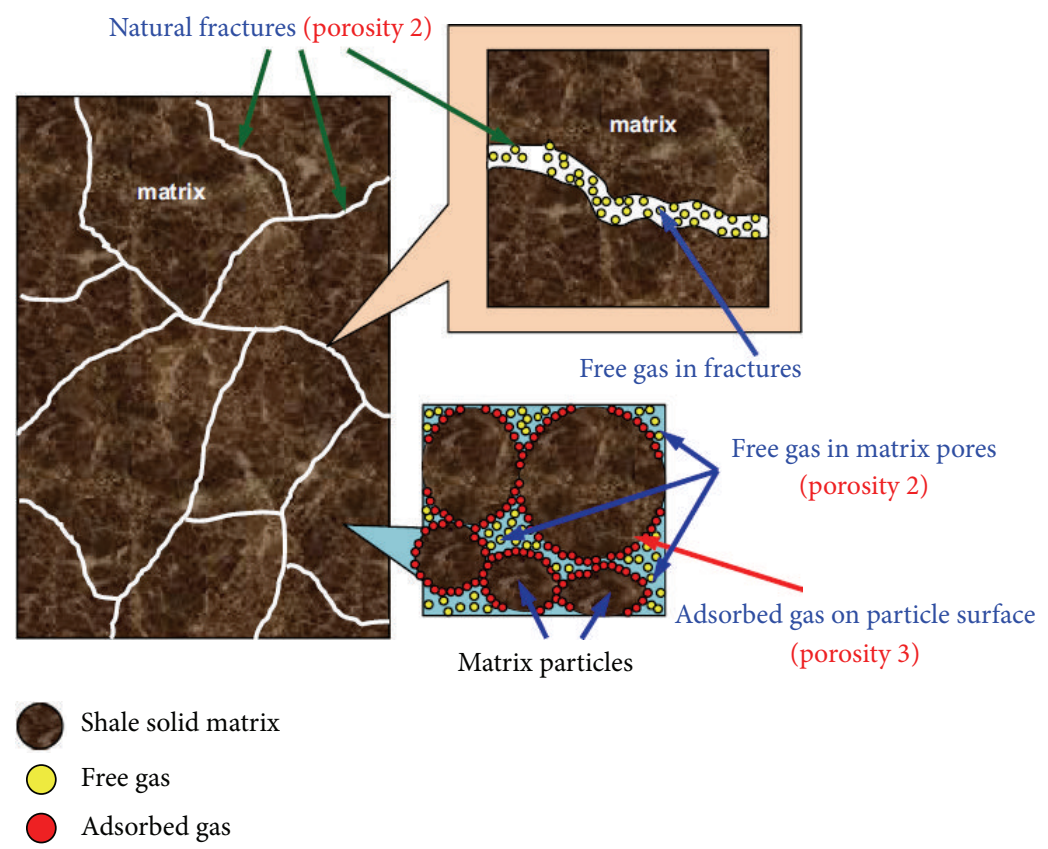

FIgURE 2: The physical model of triporosity model $[12,17]$.

For gas flow in porous media, in order to linearize the strong nonlinear flowing equations, the pseudopressure is needed, which is expressed as follows:

$$
m\left(p_{\mathrm{f}}\right)=\int_{p_{\mathrm{o}}}^{p_{\mathrm{f}}} \frac{2 p}{Z \mu_{\mathrm{g}}} \mathrm{d} p .
$$

With consideration of the macroscopic pores in the matrix as media for gas to flow through, the model turns into a "triporosity" model. Because the assumption of pseudosteady state flow of gas from matrix pores to microfracture system is made, the following variables are defined for the derivation process:

$$
\begin{aligned}
& r_{\mathrm{D}}=\frac{r}{L_{\mathrm{ref}}}, \\
& t_{\mathrm{D}}=\frac{k_{\mathrm{f}} t}{\left(\phi_{\mathrm{m}} c_{\mathrm{mgi}}+\phi_{\mathrm{f}} c_{\mathrm{fgi}}\right) \mu_{\mathrm{gi}} L_{\mathrm{ref}}^{2}}, \\
& \omega_{\mathrm{f}}=\frac{\phi_{\mathrm{f}} c_{\mathrm{fgi}}}{\phi_{\mathrm{m}} c_{\mathrm{mgi}}+\phi_{\mathrm{f}} c_{\mathrm{fgi}}},
\end{aligned}
$$




$$
\begin{aligned}
\omega_{\mathrm{d}} & =\frac{\phi_{\mathrm{m}} c_{\mathrm{d}}}{\phi_{\mathrm{m}} c_{\mathrm{mgi}}+\phi_{\mathrm{f}} c_{\mathrm{fgi}}}, \\
\lambda & =\alpha \frac{k_{\mathrm{m}}}{k_{\mathrm{f}}} L_{\mathrm{ref}}^{2}, \\
\Delta m_{\mathrm{f}} & =m\left(p_{\mathrm{i}}\right)-m\left(p_{\mathrm{f}}\right), \\
\Delta m_{\mathrm{m}} & =m\left(p_{\mathrm{i}}\right)-m\left(p_{\mathrm{m}}\right), \\
c_{\mathrm{d}} & =\frac{2 T p_{\mathrm{sc}}}{\phi_{\mathrm{m}} \mu_{\mathrm{gi}} T_{\mathrm{sc}}} \frac{\left(1-\phi_{\mathrm{f}}-\phi_{\mathrm{m}}\right) G_{\mathrm{L}} m\left(p_{\mathrm{L}}\right)}{\left[m\left(p_{\mathrm{L}}\right)+m\left(p_{\mathrm{m}}\right)\right]^{2}} .
\end{aligned}
$$

By substituting the above variables into the governing equations of both matrix and natural microfractures systems, the general equation of microfracture systems under different flow mechanisms is

$$
\frac{1}{r_{\mathrm{D}}^{2}} \frac{\partial}{\partial r_{\mathrm{D}}}\left(r_{\mathrm{D}}^{2} \frac{\partial \Delta \bar{m}_{\mathrm{f}}}{\partial r_{\mathrm{D}}}\right)=f(s) \Delta \bar{m}_{\mathrm{f}} .
$$

Note that $f(s)$ is a parameter group for the mechanism flow model used in this paper, which is described with the following equation:

$$
f(s)=\frac{\lambda\left(1+\omega_{\mathrm{d}}\right)+\omega_{\mathrm{f}}\left(1-\omega_{\mathrm{f}}+\omega_{\mathrm{d}}\right) s}{\lambda+\left(1-\omega_{\mathrm{f}}+\omega_{\mathrm{d}}\right) s} s .
$$

Through carefully analyzing the expression of above equation, it can be easily concluded that the mechanism model proposed in this paper can be transferred into the conventional dual-porosity model by equaling $\omega_{\mathrm{d}}$ to 0 , which means there is no adsorbed gas in the matrix system.

\section{Mathematical Model}

In order to obtain the solution of fractured horizontal well in closed rectangular shale gas reservoir with Green's and source function, the continuous point and source functions must be derived firstly. Figure 3 shows a physical model of a fractured horizontal well in closed rectangular shale gas reservoir. In order to make the problem more tractable, we assume that all hydraulic fractures are transverse and fully penetrated along the well and the orientation of horizontal well is distributed along the $y$ coordinate; all the fractures are infinite conductivity and neglect the fluid flow from the microfractured to the horizontal well; the formation thickness and the fracture heights are $h$.

The continuous line source function in a rectangular closed shale gas reservoir in Laplace domain is [19]

$$
\begin{aligned}
& \Delta \bar{m}_{\mathrm{f}}=\frac{p_{\mathrm{sc}} T}{T_{\mathrm{sc}}} \frac{q_{\mathrm{scL}}}{\pi k_{\mathrm{f}} L_{\mathrm{ref}} h_{\mathrm{D}} s} \\
& \cdot \frac{\pi}{x_{\mathrm{eD}}}\left\{\frac{\cosh \left(\sqrt{u} \widetilde{y}_{\mathrm{D} 1}\right)+\cosh \left(\sqrt{u} \widetilde{y}_{\mathrm{D} 2}\right)}{\sqrt{u} \sinh \left(\sqrt{u} y_{\mathrm{eD}}\right)}\right.
\end{aligned}
$$

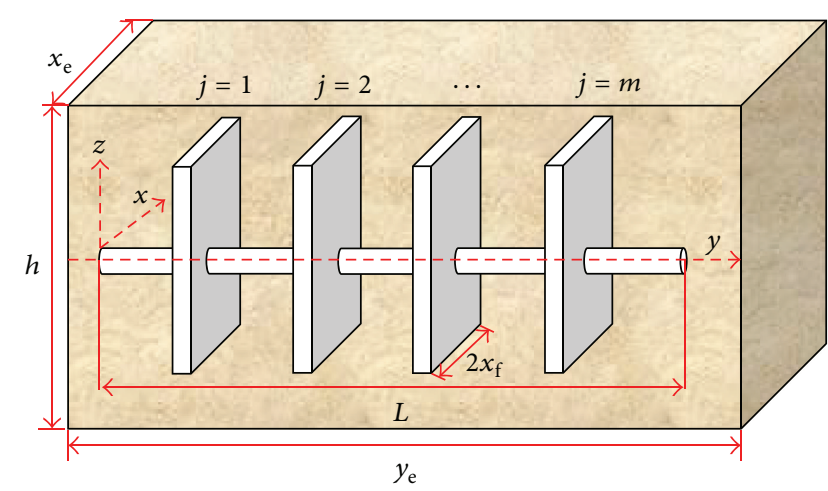

Figure 3: Physical model of a multifractured horizontal well in a closed rectangular shale gas reservoir.

$$
\begin{aligned}
& +2 \sum_{k=1}^{+\infty} \cos \left(k \pi \frac{x_{\mathrm{D}}}{x_{\mathrm{eD}}}\right) \cos \left(k \pi \frac{x_{\mathrm{wD}}}{x_{\mathrm{eD}}}\right) \\
& \left.\cdot \frac{\cosh \left(\sqrt{\varepsilon_{k}} \tilde{y}_{\mathrm{D} 1}\right)+\cosh \left(\sqrt{\varepsilon_{k}} \widetilde{y}_{\mathrm{D} 2}\right)}{\sqrt{\varepsilon_{k}} \sinh \left(\sqrt{\varepsilon_{k}} y_{\mathrm{eD}}\right)}\right\},
\end{aligned}
$$

where

$$
\begin{aligned}
\zeta_{\mathrm{D}} & =\frac{\zeta}{L_{\text {ref }}} \sqrt{\frac{k}{k_{\zeta}}} \quad(\zeta=x, y, z), \\
h_{\mathrm{D}} & =\frac{h}{L_{\text {ref }}} \sqrt{\frac{k}{k_{z}}} \\
\tilde{y}_{\mathrm{D} 1} & =y_{\mathrm{eD}}-\left|y_{\mathrm{D}}-y_{\mathrm{wD}}\right|, \\
\tilde{y}_{\mathrm{D} 2} & =y_{\mathrm{eD}}-\left|y_{\mathrm{D}}+y_{\mathrm{wD}}\right|, \\
\varepsilon_{k} & =u+\frac{\pi^{2} k^{2}}{x_{\mathrm{eD}}^{2}} \\
\varepsilon_{n} & =u+\frac{n^{2} \pi^{2}}{h_{\mathrm{D}}^{2}}, \\
\varepsilon_{k, n} & =u+\frac{n^{2} \pi^{2}}{h_{\mathrm{D}}^{2}}+\frac{\pi^{2} k^{2}}{x_{\mathrm{eD}}^{2}} .
\end{aligned}
$$

According to the continuous line solution in a rectangular closed shale gas reservoir derived above, the pressure drop of the $i$ th element fracture on the point of $\left(x_{D}, y_{D}\right)$ can be obtained by integrating the continuous line source function of (8) along the fracture if the flux of each fracture element is uniform (the schematic is shown in Figure 4):

$$
\Delta \bar{m}_{\mathrm{f} i}\left(x_{\mathrm{D}}, y_{\mathrm{D}}\right)=\int_{\Gamma} \Delta \bar{m}_{\mathrm{fL}}\left(x_{\mathrm{D}}, y_{\mathrm{D}}, x_{\mathrm{wD} i}, y_{\mathrm{wD} i}, s\right) \mathrm{d} l .
$$

Then, the line integral in the equation above can be converted into the integration of fracture unit along $x$ 


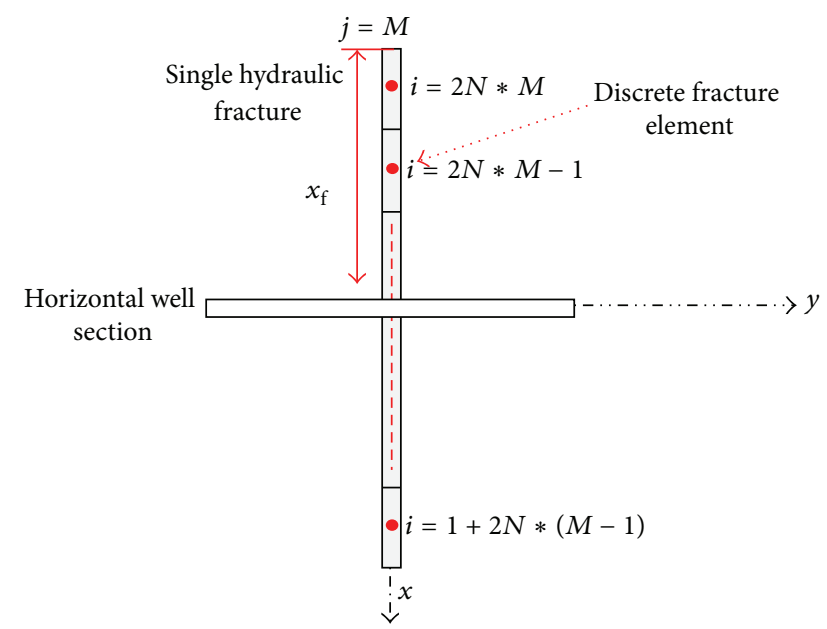

FIGURE 4: Discretization of one fracture in fracture system.

direction reasonably in that the directions of fractures in the model are parallel to the $x$-axis, which can be written as follows:

$$
\begin{aligned}
& \Delta \bar{m}_{\mathrm{f} i}\left(x_{\mathrm{D}}, y_{\mathrm{D}}\right) \\
& \quad=\int_{x_{\mathrm{m} i}-\Delta L_{\mathrm{f} i} / 2}^{x_{\mathrm{m} i}+\Delta L_{\mathrm{f} i} / 2} \Delta \bar{m}_{\mathrm{fL}}\left(x_{\mathrm{D}}, y_{\mathrm{D}}, x_{\mathrm{wD} i}, y_{\mathrm{wD} i}, s\right) \mathrm{d} x_{\mathrm{w}} .
\end{aligned}
$$

Substituting (9) into (12) results in following equation:

$$
\begin{gathered}
\Delta \bar{m}_{\mathrm{f} i}=\frac{p_{\mathrm{sc}} T}{T_{\mathrm{sc}}} \frac{q_{\mathrm{scL} i}}{\pi k_{\mathrm{f}} L_{\mathrm{ref}} h_{\mathrm{D}} s} \frac{\pi}{x_{\mathrm{eD}}}\left\{\Delta L_{\mathrm{f} i}\right. \\
\cdot \frac{\cosh \left(\sqrt{u} \widetilde{y}_{\mathrm{D} 1}\right)+\cosh \left(\sqrt{u} \widetilde{y}_{\mathrm{D} 2}\right)}{\sqrt{u} \sinh \left(\sqrt{u} y_{\mathrm{eD}}\right)} \\
+2 L_{\mathrm{ref}} \int_{-\Delta L_{\mathrm{fD} i} / 2}^{+\Delta L_{\mathrm{fD} i} / 2+\infty} \sum_{k=1}^{+\infty} \cos \left(k \pi \frac{x_{\mathrm{D}}}{x_{\mathrm{eD}}}\right) \\
\cdot \cos \left(k \pi \frac{x_{\mathrm{mD} i}+\alpha}{x_{\mathrm{eD}}}\right) \\
\cdot \frac{\cosh \left(\sqrt{\varepsilon_{k}} \widetilde{y}_{\mathrm{D} 1}\right)+\cosh \left(\sqrt{\varepsilon_{k}} \widetilde{y}_{\mathrm{D} 2}\right)}{\sqrt{\varepsilon_{k}} \sinh \left(\sqrt{\varepsilon_{k}} y_{\mathrm{eD}}\right)} \mathrm{d} \alpha .
\end{gathered}
$$

Defining the following dimensionless production and dimensionless pseudopressure, the expressions are

$$
\begin{gathered}
q_{\mathrm{D} i}=\frac{q_{\mathrm{sc} i} \Delta L_{\mathrm{f} i}}{q_{\mathrm{sc}}}, \\
m_{\mathrm{fD}}=\frac{\pi k_{\mathrm{fh}} h T_{\mathrm{sc}}}{p_{\mathrm{sc}} T q_{\mathrm{sc}}} \Delta m_{\mathrm{f}} .
\end{gathered}
$$

The dimensionless pseudopressure drop in an arbitrary point caused by an arbitrary element $i$ can be obtained by substituting (14) into (13):

$$
\begin{gathered}
\bar{m}_{\mathrm{fD} i}=q_{\mathrm{D} i} A_{j i}=\frac{q_{\mathrm{D} i}}{s} \\
\cdot \frac{\pi}{x_{\mathrm{eD}}}\left\{\frac{\cosh \left(\sqrt{u} \widetilde{y}_{\mathrm{D} 1}\right)+\cosh \left(\sqrt{u} \widetilde{y}_{\mathrm{D} 2}\right)}{\sqrt{u} \sinh \left(\sqrt{u} y_{\mathrm{eD}}\right)}+\frac{2}{\Delta L_{\mathrm{fD} i}}\right. \\
\cdot \int_{-\Delta L_{\mathrm{fD} i} / 2}^{\Delta L_{\mathrm{fD} i} / 2} \cos \left(k \pi \frac{x_{\mathrm{D}}}{x_{\mathrm{eD}}}\right) \cos \left(k \pi \frac{x_{\mathrm{mD} i}+\alpha}{x_{\mathrm{eD}}}\right) \\
\left.\cdot \frac{\cosh \left(\sqrt{\varepsilon_{k}} \widetilde{y}_{\mathrm{D} 1}\right)+\cosh \left(\sqrt{\varepsilon_{k}} \widetilde{y}_{\mathrm{D} 2}\right)}{\sqrt{\varepsilon_{k}} \sinh \left(\sqrt{\varepsilon_{k}} y_{\mathrm{eD}}\right)}\right\} \mathrm{d} \alpha,
\end{gathered}
$$

where $A_{j i}$ (both $i$ and $j$ vary in the range 1 to $2 N M$ ) represents the pseudopressure drop of element $j$ at the location of element $i$.

Since the hydraulic fractured horizontal well consists of many discrete fracture units, the pressure of an arbitrary point in formation is the result of superposition by discrete units according to the assumption of this model. On the basis of superposition principle, the pressure drop at nodal point caused by the total element can be obtained as follows:

$$
\bar{m}_{\mathrm{D}}\left(x_{\mathrm{D} j}, y_{\mathrm{D} j}\right)=\sum_{i=1}^{M * 2 N} q_{\mathrm{D} i} A_{j i}\left(x_{\mathrm{D} i}, y_{\mathrm{D} i}, x_{\mathrm{D} j}, y_{\mathrm{D} j}, s\right) .
$$

The hypothesis of infinite conductivity fracture leads to the same pressure at every point inside the fracture element, which is equal to the bottom-hole pressure, which yields

$$
\bar{m}_{\mathrm{wD}}=\bar{m}_{\mathrm{D}}\left(\widehat{x}_{\mathrm{D} j}, \widehat{y}_{\mathrm{D} j}\right) .
$$

Besides, the total flow rate is the summation of the rate from each fracture as a result of the material balance theory, so

$$
\sum_{i=1}^{M * 2 N} q_{\mathrm{D} i}=1
$$

Although the solution of the mathematical model in this paper is based on the foundation of gas well producing at a constant rate, when the gas well is producing at a constant wellbore pressure, the corresponding dimensionless production rate of wells can be obtained through the following equation:

$$
\bar{q}_{\mathrm{D}}=\frac{1}{\bar{m}_{\mathrm{fD}} \times s^{2}}
$$

Through combining (19) with other equations presented above, we can get the solution for a multifractured horizontal well producing at a constant wellbore pressure in a rectangular reservoir. 
TABLE 1: Basic data used in analysis of examples.

\begin{tabular}{lc}
\hline Input parameters & Value \\
\hline Initial reservoir pressure, $p_{\mathrm{i}}(\mathrm{MPa})$ & 25 \\
Initial reservoir temperature, $T(\mathrm{~K})$ & 320 \\
Formation thickness, $h(\mathrm{~m})$ & 60 \\
Half fracture length, $x_{\mathrm{f}}(\mathrm{m})$ & 30 \\
Gas specify gravity, $\gamma($ dimensionless $)$ & 0.65 \\
Initial compressibility of gas, $c_{\mathrm{gi}}\left(\mathrm{MPa}^{-1}\right)$ & 0.01 \\
Flowing pressure in bottom hole, $p_{\mathrm{wf}}(\mathrm{MPa})$ & 1 \\
Permeability of microfracture system, $k_{\mathrm{f}}(\mathrm{mD})$ & 0.01 \\
Permeability of matrix pores system, $k_{\mathrm{m}}(\mathrm{mD})$ & 0.0001 \\
Porosity of microfracture system, $\emptyset_{\mathrm{f}}(\mathrm{dimensionless})$ & 0.02 \\
Porosity of matrix pores system, $\emptyset_{\mathrm{m}}(\mathrm{dimensionless})$ & 0.12 \\
Skin factor, $S_{\text {kin }}($ dimensionless $)$ & 0.1 \\
Wellbore storage coefficient, $C_{\mathrm{D}}\left(\mathrm{m}^{3} / \mathrm{MPa}\right)$ & $10^{-6}$ \\
Langmuir pressure, $p_{\mathrm{L}}(\mathrm{MPa})$ & 4 \\
Langmuir volume, $G_{\mathrm{L}}\left(\mathrm{m}^{3} / \mathrm{m}^{3}\right)$ & 10 \\
Number of fractures, $M($ integer $)$ & 3 \\
Effective horizontal well length, $L(\mathrm{~m})$ & 1200 \\
Outer boundary size in $x$-axis, $x_{\mathrm{e}}(\mathrm{m})$ & 400 \\
Outer boundary size in $y$-axis, $y_{\mathrm{e}}(\mathrm{m})$ & 2000 \\
Shape factor, $\alpha\left(1 / \mathrm{m}^{2}\right)$ & $10^{-5}$ \\
\hline
\end{tabular}

\section{Results, Discussion, and Sensitive Analysis}

In the above section, we have analyzed the well production rate solving process in detail and the corresponding coefficient matrix can be easily assembled and solved with Gaussian elimination method. In this section, with the aid of computer program techniques and Stehfest numerical inversion method [20], the relationship of well production rate and its corresponding cumulative production with time can be drawn on a rectangular coordinate system. The synthetic data used are listed in Table 1.

5.1. Effect of Adsorption Gas Volume. As a significant part of gas component in shale gas reservoirs, adsorption gas originally attaching on surface of shale matrix has great effect on gas production behavior of multistage fractured horizontal wells. Figure 5 illustrates the effect caused by desorption gas volume on production rate and its corresponding cumulative production. It clearly shows that, with the increasing of desorption gas volume, gas production will become larger, which is also true to cumulative gas production. As is known to us all, the free gas is produced firstly at the beginning of production. With the pressure of reservoir decreasing, more and more adsorbed gas will be desorbed from matrix surface and then becomes free gas in macropores of matrix system.

5.2. Effect of Fracture Number. As a critical sensitive factor of gas production in multifractured horizontal wells, the numbers of hydraulic fracture immediately affect production performance. Figure 6 reflects the influence on production rate decline caused by different numbers of hydraulic fractures. It shows that the more fractures there are, the higher production

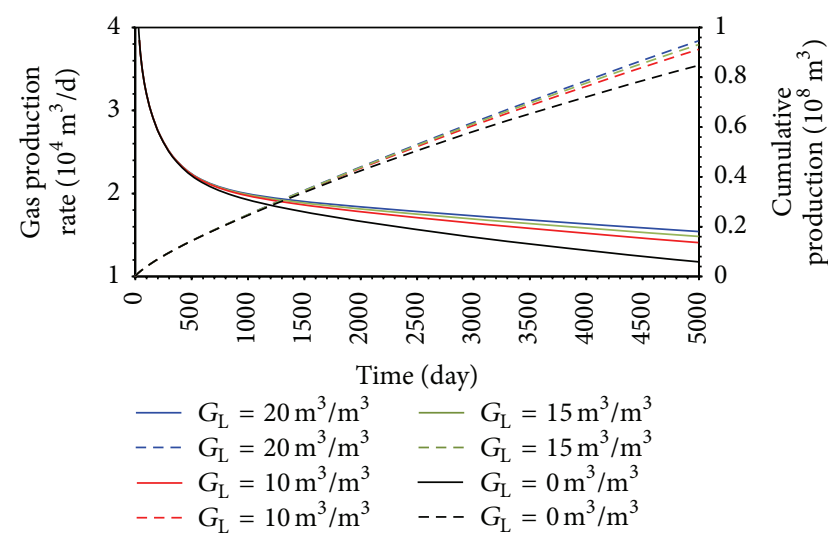

FIGURE 5: Effect of adsorption gas volume $G_{\mathrm{L}}$ on production behavior.

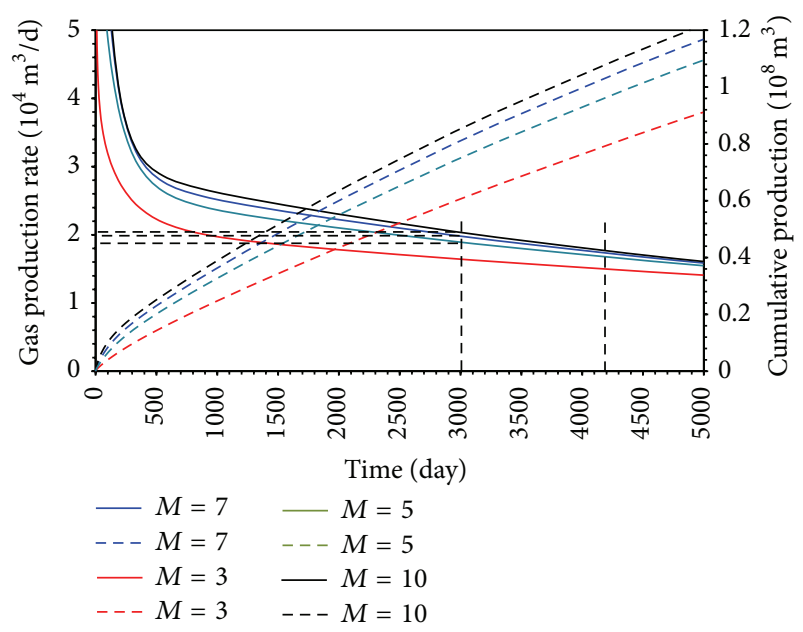

Figure 6: Effect of fracture number $(M)$ on production behavior.

rate we will get during the early flow period. Compared to the situation of $M=3$, the other three situations $(M=5$, $7,10)$ have a larger production rate. With the increasing of production time, the difference of production rate between different fracture numbers is becoming smaller. If we set the production time at $t=3000$ days, which means the well will produce nearly 10 years with constant bottom-hole pressure under same condition, it can be clearly seen from the curves that the difference of production rate for $M=5$ and $M=7$ is nearly $0.2 \times 10^{4} \mathrm{~m}^{3} /$ day, which is a very considerable rate for shale gas reservoir. But the difference for $M=7$ and $M=10$ is nearly $0.04 \times 10^{4} \mathrm{~m}^{3} /$ day, which is negligible comparing to the hydraulic fracturing cost. And also, if we set the production time at 4200 days, the same laws can be obtained. So, under this situation, the optimum fracture number can be selected as 7. Due to the fact that real formation characteristic is very complex and sometimes the induced fractures can be formed during the fracturing process, this conclusion maybe has some deviation with the practice situation.

5.3. Effect of Matrix System Permeability. As matrix is the main storage place of shale gas, the permeability of matrix 


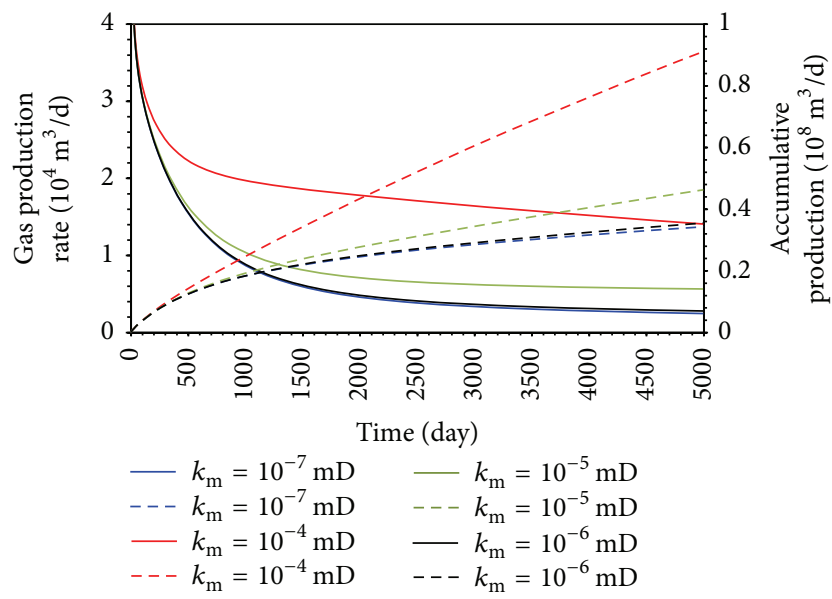

FIGURE 7: Effect of matrix system permeability $\left(k_{\mathrm{m}}\right)$ on production behavior.

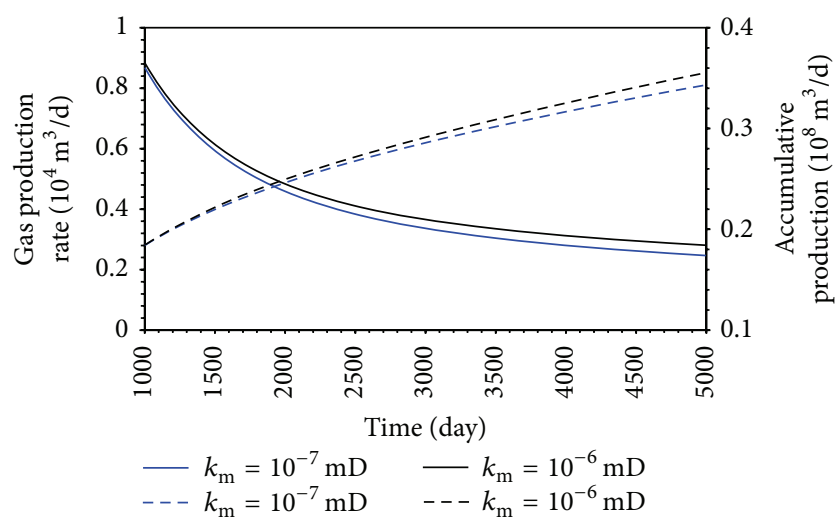

FIgURE 8: Comparing the results when $k_{\mathrm{m}}$ equals $10^{-6} \mathrm{mD}$ and $10^{-7} \mathrm{mD}$.

system plays a vital role in the process of production, which can be seen from Figure 7. The higher the matrix permeability is, the higher the well production rate will be. But when the matrix permeability increases to a certain value, the increment of the production is less (see Figure 8), such as $k_{\mathrm{m}}$ $=10^{-6} \mathrm{mD}$ and $10^{-7} \mathrm{mD}$, which means there is a critical value for $k_{\mathrm{m}}$. In this case, the critical value can be set as $10^{-6} \mathrm{mD}$.

5.4. Effect of Microfracture System Permeability. As a typical characteristic of shale gas reservoir, the influence of microfracture system was often neglected by previous studies. As the channel between the shale matrix and hydraulic fractures, the permeability of natural fracture has a certain effect on production behavior of fractured horizontal wells, which can be seen from Figure 9. As we can see, production rate and cumulative gas will ascend along with the value of natural fractures permeability increasing. Although the layer pressure decreases constantly at the early stage of production, it is always beyond the value of desorption pressure. At intermediate and late stage, the formation pressure is low enough and adsorption gas begins to be desorbed, so the influence of natural fractures' permeability will come into effect.

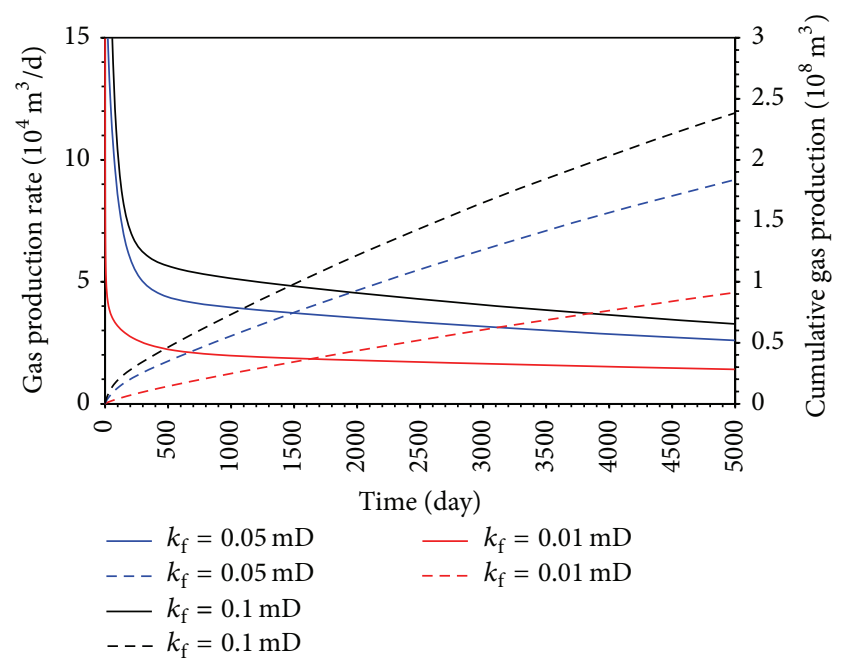

Figure 9: Effect of microfracture system permeability $\left(k_{\mathrm{f}}\right)$ on production behavior.

But there is one point we should notice that no matter what product condition is, production rate and cumulative gas will tend to be stable in late period due to the limitation of total reserve of shale gas reservoir. And the larger the microfracture permeability is, the larger the stable productivity will be. So, for the economic development of unconventional gas reservoir, the areas with microfracture developed should be treated as sweet spot to preferentially exploit.

\section{Conclusions}

A new physical triple-porosity model of a multifractured horizontal well in a closed rectangular shale gas reservoir was built with consideration of adsorption and desorption process in stable state or pseudosteady state. The point source function and superposition principle were used to establish the mathematical model to describe the flow process of shale gas in formation. From the above discussion, the following conclusions can be summarized:

(1) Due to the distribution of constant pressure curves in multistage fractured horizontal wells, the outer boundary of the physical model in this paper was considered to be a rectangular closed reservoir. It is closer to practical situations and the solutions can be calculated by Laplace transformation and numerical inversion conveniently.

(2) As a main component of gas production rate, adsorption gas plays an important role in production behavior. With more adsorption gas, there are more production rates. Besides, owing to the process of desorption, the effect of adsorption gas volume comes in intermediate and late production periods. But it will not influence the total production of shale gas reservoir. 
(3) Hydraulic fracture which was regarded as primary channel for gas seepage is another critical factor when analyzing the production decline of multifractured horizontal well in shale gas reservoir. To a certain extent, the production rate will ascend with hydraulic fracture number increasing, but it does not mean that the more fractures the better. According to different reservoir conditions, the optimum fracture number should be utilized to solve different problems.

(4) The effect of matrix system permeability, which reflects the connectivity between shale matrix and fracture system, is more obvious in intermediate and late production stages. The higher the permeability of matrix is, the better the gas production rates are. But the ultimate gas recovery will not be affected.

(5) The permeability of microfractures also has a certain effect on production behavior, which is the bridge between shale matrix and hydraulic fractures. Similarly, the effect of them is more evident in intermediate and late production periods. Moreover, gas production rate has a positive correlation with the permeability of these natural fractures, but at later stage of production, all of the production rate and cumulative gas will tend to be stable.

\section{Nomenclature}

$c_{\text {fgi }}: \quad$ Initial gas compressibility in fracture, $\mathrm{Pa}^{-1}$

$c_{\text {mgi }}$ : Initial gas compressibility in matrix, $\mathrm{Pa}^{-1}$

$G_{\mathrm{L}}$ : Langmuir volume, $\mathrm{m}^{3} / \mathrm{m}^{3}$

$h$ : $\quad$ Formation thickness, $\mathrm{m}$

$k_{\mathrm{f}}$ : Permeability of microfracture system, $10^{-15} \mathrm{mD}$

$k_{\mathrm{fh}}$ : Horizontal permeability of fracture system, $10^{-15} \mathrm{mD}$

$k_{\mathrm{m}}$ : Permeability of matrix pores system, $\mathrm{mD}$

$L: \quad$ Effective horizontal well length, $m$

$L_{\text {ref }}$ : Reference length, $\mathrm{m}$

$\Delta L_{\mathrm{f} i}$ : Length of the $i$ th element of the hydraulic fractures, $m$

$M$ : Number of fractures, integer

$N$ : Discrete number of half fractures, integer

$\Delta m:$ Pseudopressure drop, $\mathrm{Pa}$

$m_{\mathrm{fD}}$ : Dimensionless pseudopressure

$p_{\mathrm{L}}$ : Langmuir pressure, $\mathrm{Pa}$

$p_{\mathrm{f}}: \quad$ Pressure in fracture, $\mathrm{MPa}$

$p_{\mathrm{m}}$ : Pressure in matrix, $\mathrm{MPa}$

$p_{\mathrm{o}}$ : Reference pressure, $\mathrm{Pa}$

$p_{\text {sc }}$ : Pressure at standard condition, $0.10325 \times 10^{6} \mathrm{~Pa}$

$q_{\mathrm{sc}}$ : Gas production rate in standard condition, $\mathrm{m}^{3} / \mathrm{s}$

$q_{\mathrm{m}}$ : Flow rate of free gas from shale matrix to fractures, $\mathrm{kg} /\left(\mathrm{m}^{3} \cdot \mathrm{s}\right)($ see $(2))$

$q_{\text {des }}$ : Diffusion rate of shale gas from shale matrix to matrix micropores, $\mathrm{m}^{3} / \mathrm{s}$ (see (3))

$\begin{array}{ll}q_{\mathrm{scL} i}: & \begin{array}{l}\text { Continuous line source flow rate of the } i \text { th } \\ \left.\text { discrete fracture, } \mathrm{m}^{3} / \mathrm{s} \text { (see }(2)\right)\end{array} \\ q_{\mathrm{D} i}: & \begin{array}{l}\text { Dimensionless production rate on the } i \text { th } \\ \text { element }\end{array} \\ r: & \text { Radial distance, } \mathrm{m} \\ r_{\mathrm{e}}: & \text { Radius of outer boundary, } \mathrm{m} \\ s: & \text { Laplace variable } \\ S_{\mathrm{kin}}: & \text { Skin factor, dimensionless } \\ t: & \text { Production time, day } \\ T: & \text { Temperature, } \mathrm{K} \\ T_{\mathrm{sc}}: & \text { Temperature at standard condition, } 293 \mathrm{~K} \\ Z: & \text { Gas deviation factor, fraction } \\ \alpha: & \text { Shape factor, } 1 / \mathrm{m}^{2} \\ \rho: & \text { Gas density in reservoir condition, } \mathrm{kg} / \mathrm{m}^{3} \\ \rho_{\mathrm{gm}}: & \text { Gas density in the matrix systems, } \mathrm{kg} / \mathrm{m}^{3} \\ \rho_{\mathrm{gf}}: & \text { Gas density in the fracture systems, } \mathrm{kg} / \mathrm{m}^{3} \\ \lambda: & \text { Interporosity flow coefficient, } \\ \mu: & \text { dimensionless } \\ \omega: & \text { Gas viscosity, } 10^{-3} * \mathrm{cp} \\ x, y, \text { and } z: \text { Distance coordinates, m } & \text { Storability coefficient } \\ f(s): & \text { Variables groups. } \\ & \end{array}$

Subscript

D: Dimensionless

i: Initial condition

sc: Standard state

f: Fracture system

m: Matrix system

g: Gas

w: Wellbore.

Superscript

-: Laplace domain.

\section{Conflict of Interests}

All the authors declare that there is no conflict of interests regarding the publication of this paper.

\section{Acknowledgments}

This work was financially supported by National Basic Research Program of China under Grant no. 2014CB239205 and State Key Laboratory of Shale Oil and Gas Enrichment Mechanisms and Effective Development.

\section{References}

[1] C. L. Cipolla, E. P. Lolon, J. C. Erdel, and B. Rubin, "Reservoir modeling in Shale-gas reservoirs," in Proceedings of the SPE Eastern Regional Meeting, SPE-125530-MS, Charleston, WVa, USA, September 2009.

[2] J. E. Warren and P. J. Root, "The behavior of naturally fractured reservoirs," Society of Petroleum Engineers Journal, vol. 3, no. 3, Article ID SPE-426-PA, pp. 245-255, 2013. 
[3] R. N. Horne and K. O. Temeng, "Relative productivities and pressure transient modeling of horizontal wells with multiple fractures," in Proceedings of the Middle East Oil Show, SPE29891-MS, Society of Petroleum Engineers, Manama, Bahrain, March 1995.

[4] A. L. Aboaba and Y. Cheng, "Estimation of fracture properties for a horizontal well with multiple hydraulic fractures in gas shale," in Proceedings of the SPE Eastern Regional Meeting, SPE138524-MS, Morgantown, WVa, USA, October 2010.

[5] A. Belyadi, K. Aminian, S. Ameri et al., "Performance of the hydraulically fractured horizontal wells in low permeability formation," in Proceedings of the SPE Eastern Regional Meeting, Paper SPE 139082, Morgantown, WVa, USA, October 2010.

[6] E. Ozkan, R. S. Raghavan, and O. G. Apaydin, "Modeling of fluid transfer from shale matrix to fracture network," in Proceedings of the SPE Annual Technical Conference and Exhibition, SPE134830-MS, Society of Petroleum Engineers, Florence, Italy, September 2010.

[7] J. A. Haider and A. W. Robert, "New type curves for shale gas wells with dual porosity model," in Proceedings of the Canadian Unconventional Resources Conference, Paper SPE 149367, Calgary, Canada, November 2011.

[8] Y.-L. Zhao, L.-H. Zhang, J.-X. Luo, and B.-N. Zhang, "Performance of fractured horizontal well with stimulated reservoir volume in unconventional gas reservoir," Journal of Hydrology, vol. 512, pp. 447-456, 2014.

[9] Y. L. Zhao, L. H. Zhang, Y. H. Liu, S. Hu, and Q. Liu, "Transient pressure analysis of fractured well in bi-zonal gas reservoirs," Journal of Hydrology, vol. 524, pp. 89-99, 2015.

[10] F. Kucuk and W. K. Sawyer, "Transient flow in naturally fractured reservoirs and its application to Devonian gas shales," in Proceedings of the SPE Annual Technical Conference and Exhibition, SPE Paper 9397, Dallas, Tex, USA, September 1980.

[11] H. A. Al-Ahmadi and R. A. Wattenbarger, "Triple-porosity models: one further step towards capturing fractured reservoirs heterogeneity," in Proceedings of the SPE/DGS Saudi Arabia Section Technical Symposium and Exhibition, SPE-149054-MS, Al-Khobar, Saudi Arabia, May 2011.

[12] Y.-L. Zhao, L.-H. Zhang, J.-Z. Zhao, J.-X. Luo, and B.-N. Zhang, "Triple porosity' modeling of transient well test and rate decline analysis for multi-fractured horizontal well in shale gas reservoirs," Journal of Petroleum Science and Engineering, vol. 110 , pp. 253-262, 2013.

[13] H.-T. Wang, "Performance of multiple fractured horizontal wells in shale gas reservoirs with consideration of multiple mechanisms," Journal of Hydrology, vol. 510, pp. 299-312, 2014.

[14] Y. Sang, H. Chen, S. Yang et al., "A new mathematical model considering adsorption and desorption process for productivity prediction of volume fractured horizontal wells in shale gas reservoirs," Journal of Natural Gas Science and Engineering, vol. 19, pp. 228-236, 2014.

[15] J. C. Xu, C. H. Guo, M. Z. Wei, and R. Z. Jiang, "Production performance analysis for composite shale gas reservoir considering multiple transport mechanisms," Journal of Natural Gas Science and Engineering, vol. 26, pp. 382-395, 2015.

[16] C. R. Clarkson, "Production data analysis of unconventional gas wells: review of theory and best practices," International Journal of Coal Geology, vol. 109-110, pp. 101-146, 2013.

[17] B. Song, Pressure transient analysis and production analysis for new Albany shale gas wells [M.S. thesis], Texas A\&M University, College Station, Tex, USA, 2010.
[18] J. A. Rushing, A. D. Perego, and T. A. Blasingame, "Applicability of the arps rate-time relationships for evaluating decline behavior and ultimate gas recovery of coalbed methane wells," in Proceedings of the SPE Gas Technology Symposium, pp. 247264, Alberta, Canada, June 2008.

[19] Y. L. Zhao, Research on transient seepage theory of fractured wells with complex percolation mechanism in multiscale shale gas reservoir [Ph.D. thesis], Southwest Petroleum University, Chengdu, China, 2015.

[20] H. Stehfest, "Algorithm 368: numerical inversion of Laplace transforms [D5]," Communications of the ACM, vol. 13, no. 1, pp. $47-49,1970$. 


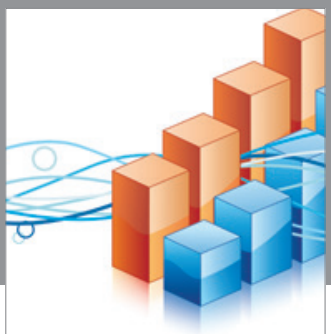

Advances in

Operations Research

vatem alat4

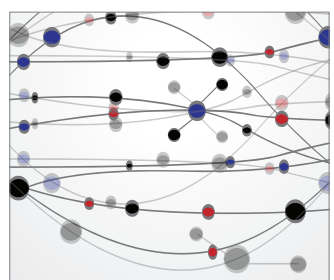

\section{The Scientific} World Journal
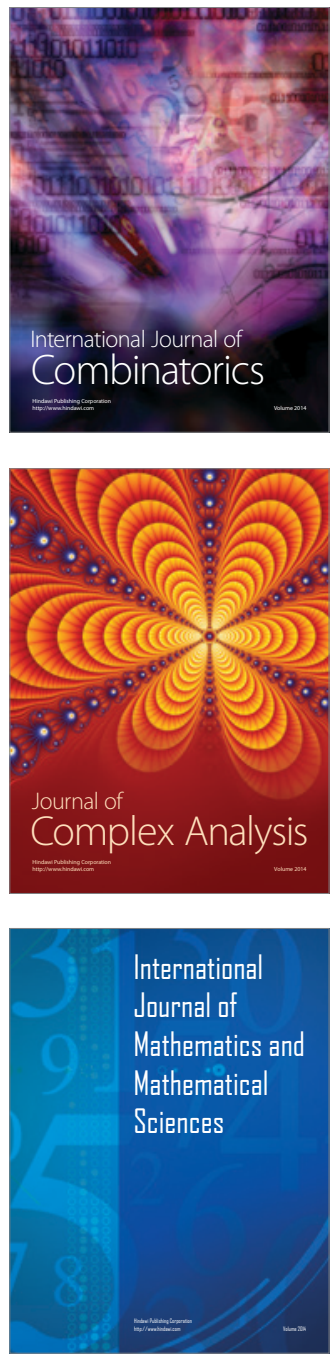
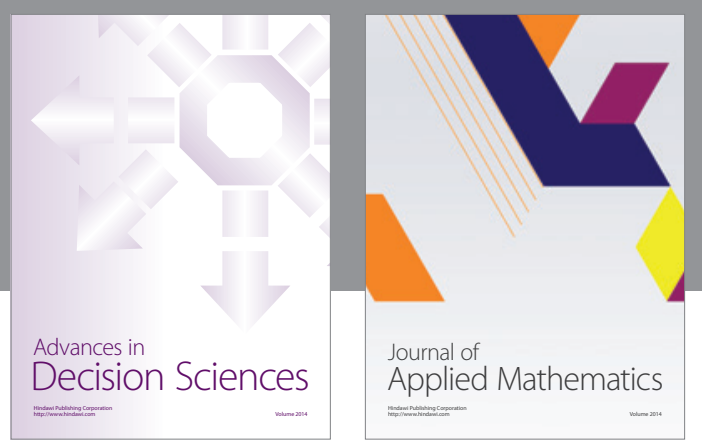

Algebra

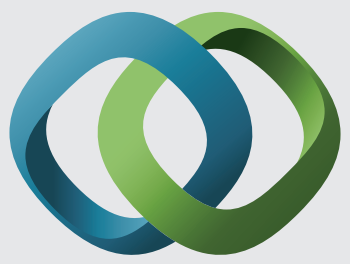

\section{Hindawi}

Submit your manuscripts at

http://www.hindawi.com
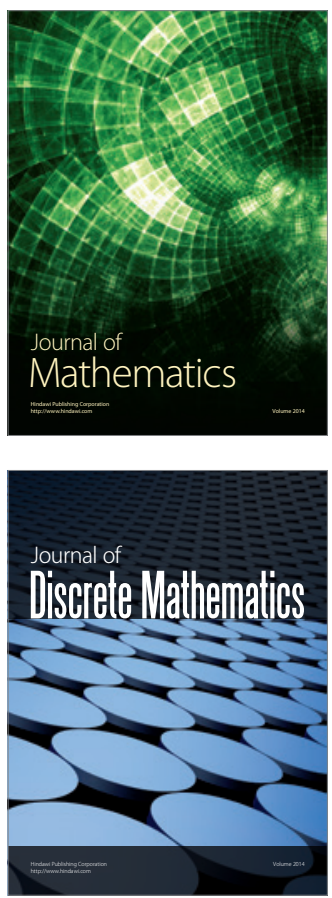

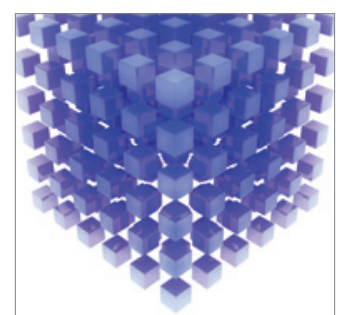

Mathematical Problems in Engineering
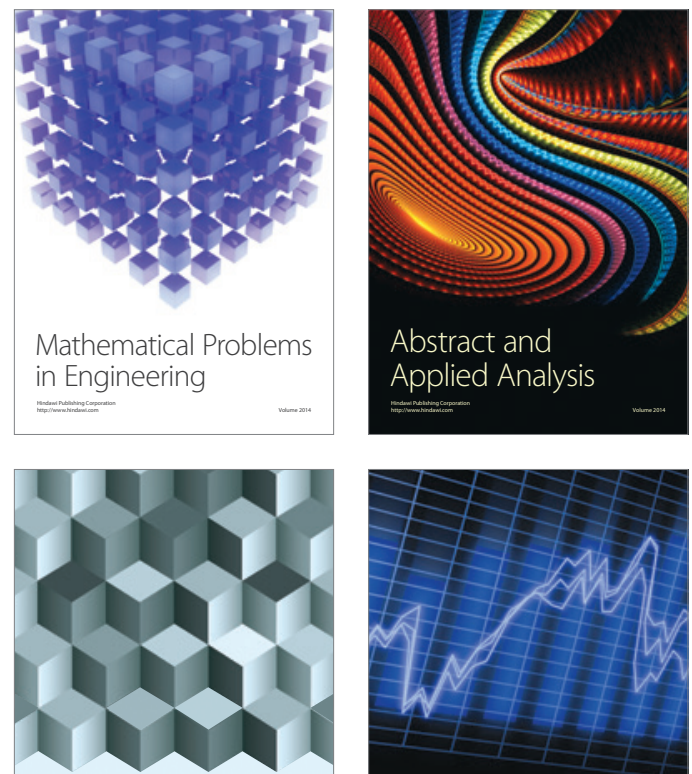

Journal of

Function Spaces

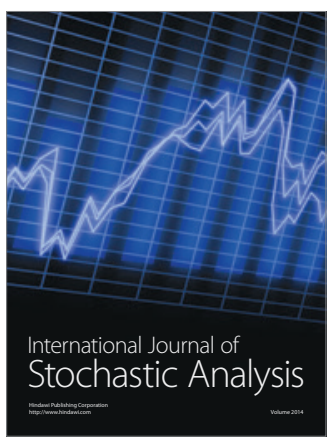

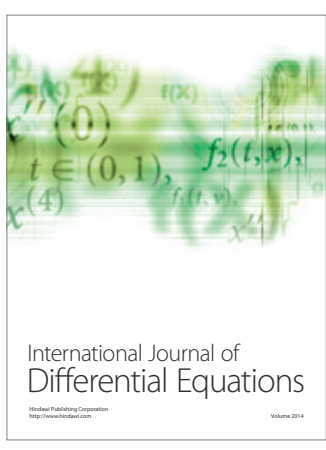
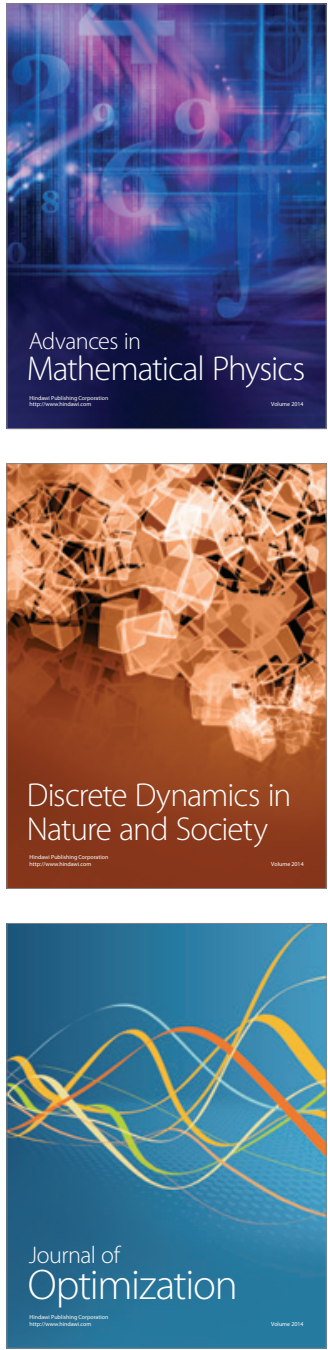